\title{
IL-10-Producing Regulatory B10 Cells Ameliorate Collagen-Induced Arthritis via Suppressing Th17 Cell Generation
}

Min Yang, ${ }^{, \dagger}$ Jun Deng, ${ }^{*}$ Yang Liu, ${ }^{*}$ King-Hung Ko, ${ }^{*}$ Xiaohui Wang, ${ }^{*}$ Zhijun Jiao, ${ }^{\neq}$ Shengjun Wang, ${ }^{\ddagger}$ Zichun Hua, ${ }^{\dagger}$ Lingyun Sun, ${ }^{\S}$ Gopesh Srivastava, ${ }^{*}$ Chak-Sing Lau, Xuetao Cao," and Liwei $\mathrm{Lu}^{\star \dagger}$

From the Department of Pathology and Center of Infection and Immunology* and the Department of Medicine, "I University of Hong Kong, Hong Kong; the State Key Laboratory of Pharmaceutical Biotechnology, ${ }^{\dagger}$ Nanjing University, Nanjing; the Department of Rheumatology and Immunology, Affiliated Drum Tower Hospital of Nanjing University Medical School, Nanjing; the Zhenjiang Key Laboratory of Medical Immunology, ${ }^{\ddagger}$ School of Medical Science and Laboratory Medicine, Jiangsu University, Zhenjiang; and the National Key Laboratory of Medical Immunology and Institute of Immunology, Second Military Medical University, Shanghai, China

IL-10-producing $\mathrm{CD} \mathrm{d}^{\mathrm{hi}} \mathrm{CD}^{+}{ }^{+} \mathrm{B}$ cells, also known as B10 cells, have been shown to possess a regulatory function in the inhibition of immune responses, but whether and how B10 cells suppress the development of autoimmune arthritis remain largely unclear. In this study, we detected significantly decreased numbers of IL-10-producing B cells, but increased IL-17producing $\mathrm{CD}^{+} \mathrm{T}(\mathrm{Th} 17)$ cells in both spleen and draining lymph nodes of mice during the acute stage of collagen-induced arthritis (CIA) when compared with adjuvant-treated control mice. On adoptive transfer of in vitro expanded B10 cells, collagen-immunized mice showed a marked delay of arthritis onset with reduced severity of both clinical symptoms and joint damage, accompanied by a substantial reduction in the number of Th17 cells. To determine whether B10 cells directly inhibit the generation of Th17 cells in culture, naive $\mathrm{CD}^{+} \mathrm{T}$ cells labeled with carboxyfluorescein succinimidyl ester (CFSE) were cocultured with B10 cells. These B10 cells suppressed Th17 cell differentiation via the reduction of STAT3 phosphorylation and retinoid-related orphan receptor yt (ROR $\gamma t)$ expression. Moreover, Th17 cells showed significantly decreased proliferation when co-cultured with B10 cells. Although adoptive transfer of Th17 cells triggered the development of collagen-induced arthritis in $\mathrm{IL}-17^{-/}$DBA/1J mice, co-transfer of $\mathrm{B10}$ cells with Th17 cells profoundly delayed the onset of arthritis. Thus, our findings suggest a novel regulatory role of B10 cells in arthritic progression via the suppression of Th17 cell generation. (Am J Pathol 2012, 180:2375-2385; http://dx.doi.org/10.1016/j.ajpath.2012.03.010)

Human rheumatoid arthritis (RA) is a chronic inflammatory disease that is characterized by extensive synovial hyperplasia, cartilage damage, bone erosion, and joint functional disability. Despite the unknown etiology of RA, IL-17-producing CD4 ${ }^{+} \mathrm{T}$ (Th17) cells have been shown to be associated with the severity of RA. ${ }^{1,2}$ The pathogenic roles of IL-17 in arthritis development have been delineated in mouse models with experimentally induced arthritis. ${ }^{3,4}$ Interestingly, newly reported findings that Th17 cells, but not $\mathrm{IL}-17^{+} \gamma \delta \mathrm{T}$ cells, ${ }^{5}$ play an essential role in driving arthritic bone destruction in mice and humans further highlight a key role of Th17 cells in the pathogenesis of autoimmune arthritis.

Recently, certain IL-10-producing B cells have been identified as regulatory $B$ (Breg) cells that can negatively regulate immune responses. ${ }^{6-8}$ There is growing evidence on the existence of Breg cells in various autoimmune mouse models including experimental autoimmune encephalomyelitis, ${ }^{9-12}$ murine lupus, ${ }^{13-15}$ as well as experimental arthritis. ${ }^{7,16-18}$ Among which, CD1d ${ }^{\text {hi }}$ CD5 ${ }^{+}$ B10 cells, one of IL-10-producing Breg cell subsets, have been shown to play a critical role in controlling the

Supported by grants from the Nanjing University State Key Laboratory of Pharmaceutical Biotechnology (KF-GN-201102), National Basic Research Program of China (2010 CB 529100), and the Hong Kong Research Grants Council, and by the Croucher Foundation (L.L.).

Accepted for publication March 1, 2012.

Supplemental material for this article can be found at http://ajp. amjpathol.org or at http://dx.doi.org/10.1016/j.ajpath.2012.03.010.

Address reprint requests to Liwei Lu, Ph.D., Department of Pathology and Center of Infection and Immunology, The University of Hong Kong, Pokfulam Rd., Hong Kong, China. E-mail: liweilu@hkucc.hku.hk. 
initial stage of experimental autoimmune encephalomyelitis by altering the interferon- $\gamma$ and tumor necrosis factor- $\alpha$ secretion and suppressing T-cell proliferation through down-regulating the ability of dendritic cells. ${ }^{10}$ Transitional 2-marginal zone precursor B cells (T2-MZP), another IL-10-producing Breg cell subset, have been shown to suppress experimental arthritis in mice significantly. ${ }^{7}$ Moreover, transfer of T2-MZP Breg cells into ar-

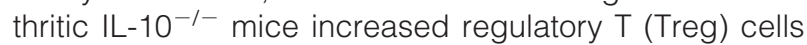
and decreased Th1 and Th17 cells, which suggest that T2-MZP Breg cells may regulate the immune balance between Treg and Th1/Th17 cells. ${ }^{19}$ An elegant study by Yanaba et al, ${ }^{20}$ using CD20 monoclonal antibodies for B-cell depletion in collagen-induced arthritis (CIA) mice, clearly revealed a crucial role of $B$ cells at the initial stage of arthritis development, but it currently is unclear whether IL-10-producing B cells show any kinetic changes during arthritis progression. Several studies using adoptive transfer of T2-MZP B cells from remission arthritic mice or total B cells from apoptotic cell-treated mice have defined the suppressive function of these B cells during autoimmune pathogenesis in mice via influencing antigen-specific effector T cells. ${ }^{7,18}$ However, it has been unclear whether adoptive transfer of in vitro expanded Breg cells could be used as a therapeutic strategy for targeting autoimmune disease. Recently, we have reported a novel function of B-cell activating factor (BAFF) in the induction of IL-10-producing $\mathrm{CD} 1 \mathrm{~d}^{\text {hi }} \mathrm{CD} 5^{+}$ B10 cells that inhibit T-cell proliferation and possess a potent regulatory function in vivo, ${ }^{17}$ but it remains to be further validated whether and how adoptive transfer of BAFF-induced B10 cells can ameliorate the disease progression of autoimmune arthritis.

In this study, we first characterized the kinetic changes of Th17 cells and IL-10-producing B cells in peripheral lymphoid organs during CIA development. It was found that at the acute phase of $\mathrm{CIA}$ (ie, within 2 weeks after the second immunization), $\mathrm{IL}-10^{+}$B cells were decreased whereas Th17 cells were increased significantly. On adoptive transfer of BAFF-induced B10 cells on the day of the second immunization, B10 cells effectively suppressed the development of arthritis with a remarkable reduction of Th17 cells. In addition, in vitro expanded B10 cells directly inhibited Th17 cell differentiation from naive $\mathrm{CD}^{+}{ }^{+} \mathrm{T}$ cells via reducing STAT3 phosphorylation and ROR $\gamma \mathrm{t}$ expression. Furthermore, although transfer of purified Th17 cells promoted arthritis development in IL-17deficient DBA mice, co-transfer of Th17 cells with B10 cells profoundly delayed the development of arthritis. Taken together, our findings have shown that BAFF-induced B10 cells can ameliorate arthritis development via suppressing Th17 cell generation, which may facilitate the development of a new cellular therapy for human RA.

\section{Materials and Methods}

\section{Mice}

$\mathrm{DBA} / 1 \mathrm{~J}$ and $\mathrm{IL}-10^{-1-} \mathrm{B} 6$ mice were purchased from the Jackson Laboratory (Bar Harbor, ME). IL-17 ${ }^{-1-}$ B6 mice were kindly provided by Professor Yoichiro Iwakura (Uni-

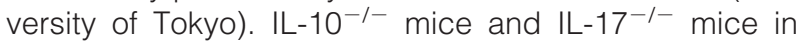
DBA/1J background were generated as previously described. ${ }^{17}$ All mice were maintained in a specific pathogen-free animal facility at the University of Hong Kong. All experimental protocols were approved by the Institutional Animal Care and Use Committee.

\section{ClA Induction and Assessment of Arthritis}

CIA was induced in DBA/1J mice or $1 \mathrm{~L}-17^{-1-} \mathrm{DBA} / 1 \mathrm{~J}$ mice (8 to 12 weeks old) as previously described. ${ }^{21}$ With the same protocol using PBS in place of bovine collagen type II (CII), adjuvant-treated DBA mice served as controls. Beginning on day 1 after the second immunization, mice were observed daily for signs of joint inflammation and scored for clinical signs. The scoring system for the severity of arthritic symptoms was the same as previously described. ${ }^{21}$

\section{Flow Cytometric Analysis}

Intracellular staining was performed as previously described. ${ }^{17}$ Briefly, cells from spleen or lymph nodes were suspended in complete medium with phorbol 12-myristate 13-acetate (PMA) $(50 \mathrm{ng} / \mathrm{mL}$; Sigma-Aldrich, St. Louis, MO), ionomycin (500 ng/mL; Sigma-Aldrich), and monensin (2 $\mu \mathrm{mol} / \mathrm{L}$; Biolegend, San Diego, CA) for 5 hours. Cells then were stained with surface markers followed by permeabilization and incubation with intracellular antibodies. Phosphorylated STAT3 staining was performed according to the manufacturer's instructions by fixation of treated cells immediately with BD Phosflow Fix buffer and Perm Buffer III (BD Biosciences, San Jose, $C A)$. RORyt staining was performed with the transcription factor staining buffer set (eBioscience, San Diego, CA). Stained cells were analyzed by a FACS Calibur flow cytometer (BD Biosciences) and data were analyzed with FlowJo software (Treestar, Ashland, OR). All antibodies used for flow cytometry staining were purchased from Biolegend, eBioscience, or BD Biosciences.

\section{Purification of $C D 4^{+} T$ Cells from Joint Tissues}

After removing skin, muscle, and bone under a dissecting microscope, joint samples of both front and hind paws were minced and digested with collagenase (Calbiochem, Billerica, MA) for 1 hour at $37^{\circ} \mathrm{C}$. Cell suspensions were filtered through a cell strainer. After lysis of red blood cells, the remaining cells were incubated with CD4microbeads (Miltenyi Biotec, Bergisch Gladbach, Germany) for 15 minutes on ice and run through a column. The purity of collected CD4 ${ }^{+}$T cells was routinely $>95 \%$.

\section{Enzyme-Linked Immunosorbent Spot Assay}

The numbers of IL-17-producing $\mathrm{CD} 4^{+} \mathrm{T}$ cells from joint tissue were determined by enzyme-linked immunosorbent spot assay. The 96-well, multiscreen, nitrocellulose, flat-bottom plates (Millipore, Billerica, MA) were coated 
with anti-mouse IL-17 (R\&D Systems, Minneapolis, MN) in coating buffer containing anti-CD3 and anti-CD28 $(1 \mu \mathrm{g} /$ $\mathrm{mL}$ ) at $4^{\circ} \mathrm{C}$ overnight. Plates were washed and then blocked with RPMI 1640 with $10 \%$ fetal bovine serum (R10) at room temperature for 1 hour. Purified $\mathrm{CD}^{+} \mathrm{T}$ cells $\left(1 \times 10^{4}\right)$ were seeded into wells and stimulated with PMA and ionomycin at $37^{\circ} \mathrm{C}$ for 4 hours. Plates were washed thoroughly before the addition of biotinylated anti-IL-17 in R10 overnight at $4^{\circ} \mathrm{C}$. After washing, plates were incubated for 1 hour at room temperature with alkaline phosphatase-conjugated streptavidin (1:1000) in R10. Then, plates were washed and developed by adding NBT/BCIP solution (Sigma-Aldrich) and the reaction was stopped by washing with tap water.

\section{Expansion of Murine B10 Cells and Adoptive Transfer of B-Cell Subsets}

Splenic $\mathrm{B}_{220^{+}} \mathrm{B}$ cells from DBA and $\mathrm{IL}-10^{-/-} \mathrm{DBA}$ mice were purified by B220-microbeads (Miltenyi Biotec) and cultured in the presence of recombinant murine BAFF (20 $\mathrm{ng} / \mathrm{mL}$; R\&D systems) for 72 hours. Cultured $B$ cells then were stained with CD19, CD1d, and CD5; CD1 $\mathrm{d}^{\text {hi }} \mathrm{CD}^{+}{ }^{+} \mathrm{B}$ cells (B10) and CD1d ${ }^{\text {lo }} \mathrm{CD}^{-} \mathrm{B}$ cells (B-ve) were sorted with an Epics Altra flow cytometer (Beckman Coulter, Fullerton, CA). The purity of sorted B-cell subsets was routinely $>95 \%$. These sorted B cells $\left(1 \times 10^{6}\right)$ were transferred intravenously into DBA/1J mice or $\mathrm{IL}-17^{-/-}$ mice on the day of the second immunization. The sham control group was injected with the same volume of PBS only. In separate experiments, CFSE-labeled sorting-purified B10 cells $\left(1 \times 10^{6}\right)$ were transferred into DBA/1J mice on the day of the second immunization for monitoring the migration route of transferred B10 cells.

\section{Histopathologic Analysis}

Joint samples were fixed in 10\% formalin for 3 days, followed by decalcification in 15\% formic acid overnight before being embedded in paraffin. Tissue sections were prepared for H\&E or Safranin O staining.

\section{Microcomputed Tomography}

Microcomputed tomography of mouse paws was performed using a SkyScan 1076 scanner (SkyScan, Kontich, Belgium). Briefly, mice were anesthetized with Hypnorm (0.5 mL/kg; Elmet, Leeds, UK) and Dormicum $(0.5 \mathrm{~mL} / \mathrm{kg})$. One of the legs was fixed in a polystyrene foam tube and then the mouse was placed horizontally in a 1076 scanner sample chamber for microcomputed tomography imaging (Roche, Basel, Switzerland). The image reconstruction was performed by using a modified Feldkamp1 algorithm using the SkyScan Nrecon2 software.

\section{Enzyme-Linked Immunosorbent Assay}

Serum levels of bovine collagen type II-specific total immunoglobulin $(\mathrm{Ig}) \mathrm{G}$, IgM, and IgG isotype were mea- sured by enzyme-linked immunosorbent assay (ELISA), as previously described. ${ }^{22}$ Levels of IL-17A in culture supernatant and synovial fluid were measured by using an IL-17A ELISA kit (Biolegend), following the manufacturer's protocol.

\section{T-Cell Subset Induction and Purification}

For Th17 cell induction, $\mathrm{CD} 4{ }^{+} \mathrm{CD} 25^{-} \mathrm{CD} 62 \mathrm{~L}^{+}$naive $\mathrm{T}$ cells isolated by the $\mathrm{CD} 4^{+} \mathrm{CD} 62 \mathrm{~L}^{+} \mathrm{T}$-Cell Isolation Kit II (Miltenyi Biotec) were cultured in a 6-well plate precoated with anti-CD3 $(1 \mu \mathrm{g} / \mathrm{mL})$ and anti-CD28 $(1 \mu \mathrm{g} / \mathrm{mL})$ in the presence of recombinant human-transforming growth factor- $\beta(3 \mathrm{ng} / \mathrm{mL})$, recombinant murine $\mathrm{IL}-6(20 \mathrm{ng} / \mathrm{mL})$, and $\mathrm{rmlL}-23(20 \mathrm{ng} / \mathrm{mL})$ for 3 days. For Treg cell induction, $\mathrm{CD} 4^{+} \mathrm{CD} 25^{-} \mathrm{CD} 2 \mathrm{~L}^{+}$naive T cells were cultured in the presence of rh-transforming growth factor- $\beta$ ( $5 \mathrm{ng} /$ $\mathrm{mL})$ with plate-bound anti-CD3 $(1 \mu \mathrm{g} / \mathrm{mL})$ and anti-CD28 $(1 \mu \mathrm{g} / \mathrm{mL})$ for 3 days. Purification of Th17 cells were performed by using the mouse IL-17 secretion and enrichment assay kit (Miltenyi Biotec), according to the manufacturer's instructions.

\section{B10 Suppresses Th17 Cell Generation}

Sorting-purified B10 cells from DBA and $\mathrm{IL}-10^{-1-} \mathrm{DBA}$ mice and $B$-ve cells from DBA mice were co-cultured with CFSE-labeled purified naive CD4 ${ }^{+} \mathrm{T}$ cells in Th17 cell polarization medium at a ratio of $1: 1$ for 72 hours before flow cytometric analysis for Th17 cell generation.

\section{Statistical Analysis}

Data are expressed as the mean \pm standard error of the mean. Unless otherwise indicated, statistical analysis was performed using the unpaired Student's $t$-test. A $P$ value $<0.05$ was considered significantly different.

\section{Results}

\section{Kinetic Changes of Th17 Cells and IL-10+ B Cells During CIA Development}

Although the pathogenic role of Th17 cells in autoimmune arthritis has been well recognized, only recently has the immunoregulatory function of Breg cells been appreciated in autoimmune diseases. To characterize the kinetic changes of Th17 cells and IL-10 $10^{+} \mathrm{B}$ cells during the development of experimental arthritis, both frequencies and absolute numbers of Th17 cells and IL- $10^{+} \mathrm{B}$ cells in the spleen and draining lymph nodes of CIA mice were determined by flow cytometric analysis. At the acute phase of CIA (ie, within 2 weeks after the second immunization), both frequencies and total numbers of Th17 cells from the spleen and draining lymph nodes showed an approximate twofold increase when compared with those from adjuvant-treated control DBA mice (Figure 1, $A$ and $C$ ). In contrast, the frequencies of $\mathrm{IL}-10^{+} B$ cells in both spleen and draining lymph nodes were decreased significantly (Figure 1B), with almost $50 \%$ of reduction in 
A

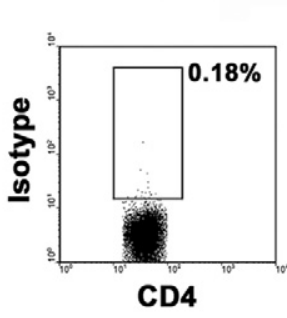

B

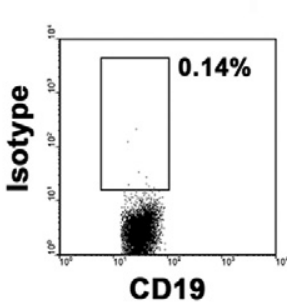

C

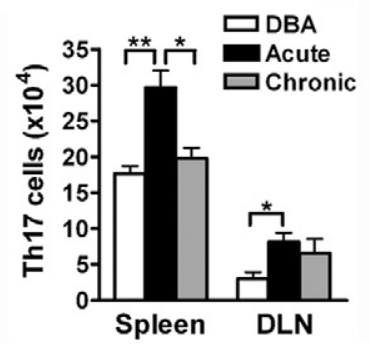

DBA

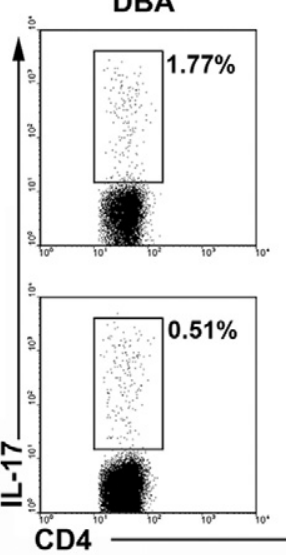

DBA

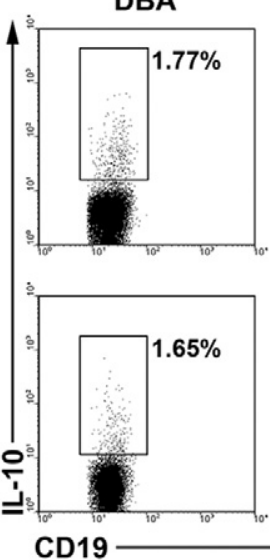

D
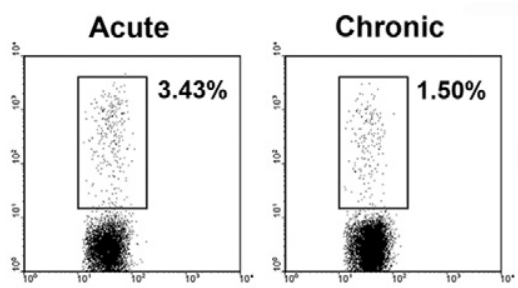

Spleen
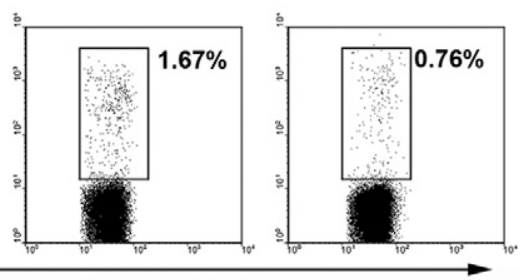

DLN
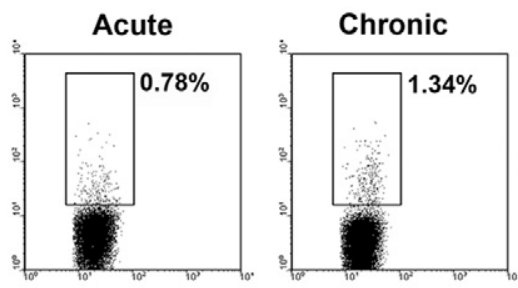

Spleen
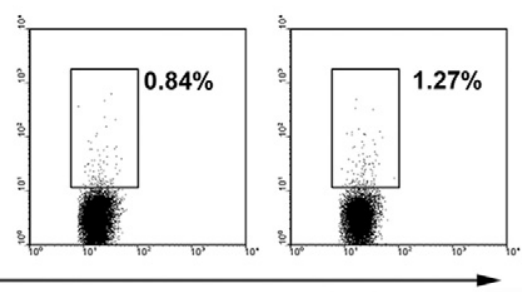

DLN

E

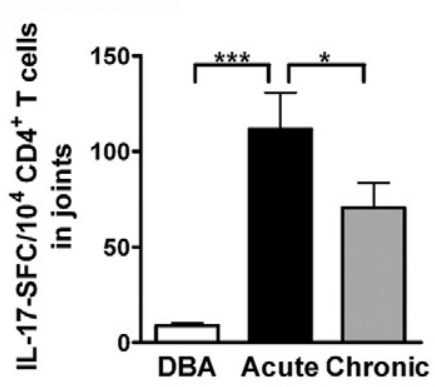

Figure 1. Kinetic changes of Th17 cells and IL- $10^{+} \mathrm{B}$ cells during CIA development. A and B: Single-cell suspensions from spleen and draining lymph nodes (DLN) of adjuvant-treated DBA mice, CIA mice at the acute phase, and CIA mice at the chronic phase were prepared for immunostaining and analyzed by flow cytometry for CD4 and IL-17 expression (A) and CD19 and IL-10 expression (B). The representative flow results indicate the frequencies of Th17 cells and IL-10 ${ }^{+}$ B cells in spleen and DLN. C and D: The total number of Th17 cells (C) and IL-10 ${ }^{+}$B cells (D) (mean \pm standard error of the mean) from 5 independent experiments with 5 mice in each group were statistically analyzed by the Student's $t$-test. ${ }^{*} P<0.05$, ${ }^{* *} P<0.01$. E: Joint samples from adjuvant-treated DBA mice and CIA mice at the acute and chronic phases were digested for CD ${ }^{+}{ }^{\top}$ T-cell isolation. CD ${ }^{+}$T cells $\left(1 \times 10^{4}\right)$ were seeded in each well. IL-17-spot-forming cells (SFC) were counted and compared. Data are derived from 5 independent experiments. ${ }^{*} P<0.05,{ }^{*}{ }^{* * *} P<0.001$.

total number of splenic IL-10+ $\mathrm{B}$ cells (Figure 1D). However, on the progression of arthritis into a chronic phase (ie, within 8 to 10 weeks after the second immunization), both frequencies and numbers of Th17 cells were reduced substantially whereas $\mathrm{IL}-10^{+} \mathrm{B}$ cells gradually were increased when compared with $\mathrm{ClA}$ mice at an acute phase.

To further examine the dynamic changes of Th17 cells in inflamed joints, $\mathrm{CD}^{+}{ }^{+} \mathrm{T}$ cells from joint tissues of control DBA mice and CIA mice at both acute and chronic phases were purified and the number of IL-17-spot-forming cells was determined by enzyme-linked immunosorbent spot analysis. Consistent with the pattern of their kinetic changes in either spleen or lymph nodes, Th17 cells also showed a profound increase in inflamed joints of CIA mice at the acute phase, followed by a significant decrease at the chronic phase (Figure 1E). These results indicate that some correlated changes exist between Th17 cells and IL $-10^{+} \mathrm{B}$ cells during the progression of arthritis.

Notably, we examined DBA mice with a similar age as chronic CIA mice to exclude the possibility that aging may affect the kinetic change of Th17 cells and/or IL-10+ $\mathrm{B}$ cells. 


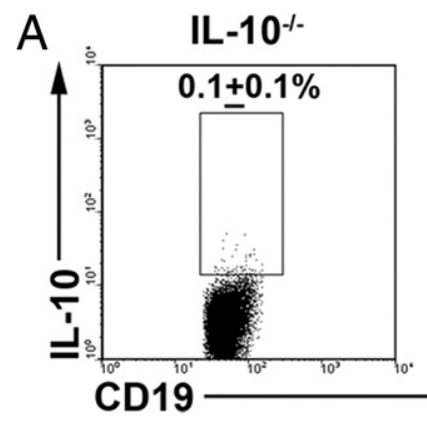

B
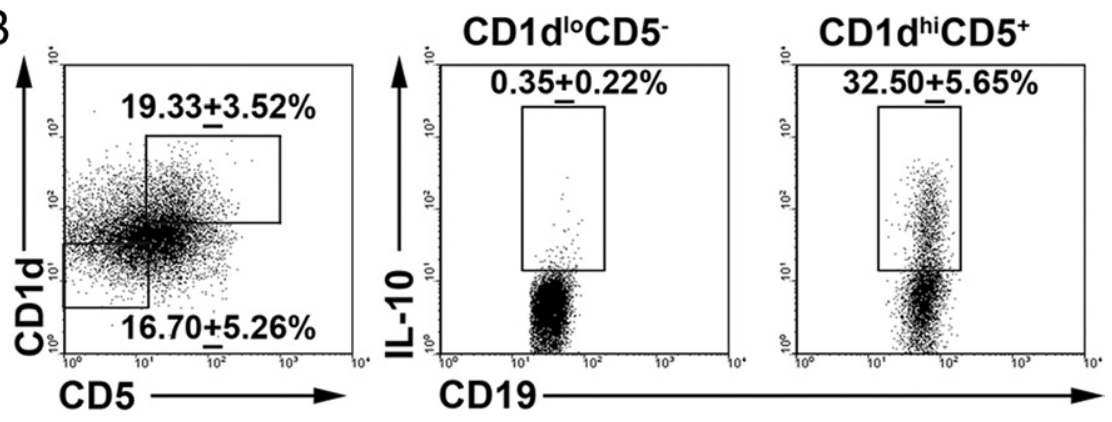

Figure 2. BAFF treatment induces the expansion of IL-10-producing B10 cells in culture. A: Flow cytometric analysis of IL-10-producing B cells. Purified splenic B cells from wild-type DBA and IL- $10^{-/-}$DBA mice were cultured with BAFF for 72 hours, treated with PMA, ionomycin, and monension for 5 hours and then immunostained with anti-CD19 and anti-IL-10. In the flow profiles, frequencies of IL-10-producing B cells (mean \pm standard error of the mean) were indicated, representative of 10 separate experiments. B $\mathrm{CD} 1 \mathrm{~d}^{\text {hi }} \mathrm{CD} 5^{+} \mathrm{B}$ cells are the major subset for IL- 10 production. The gates of BAFF-induced $\mathrm{B} 10$ and B-ve cells were shown for electronic cell sorting. Percentages of $\mathrm{IL}-10^{+} \mathrm{B}$ cells (mean \pm standard error of the mean) were indicated for $\mathrm{CD} 1 \mathrm{~d}^{\text {hi }} \mathrm{CD} 5^{+}$and $\mathrm{CD} 1 \mathrm{~d}^{\mathrm{lo}} \mathrm{CD} 5^{-}$B-cell subsets, representative of 10 separate experiments.
Similar frequencies and absolute numbers of Th17 cells and $\mathrm{IL}-10^{+} \mathrm{B}$ cells were found between older DBA mice (24 to 28 weeks old) and control DBA mice (12 to 16 weeks old) used in this study (data not shown). Thus, the dynamic change of Th17 cells and IL-10+ $\mathrm{B}$ cells during the development of arthritis appeared to be associated closely with disease progression in CIA mice.

\section{Adoptive Transfer of B10 Cells Ameliorates Arthritis Development in CIA Mice}

We previously found that BAFF-induced IL-10-producing B cells displayed a typical phenotype of $\mathrm{CD} 1 \mathrm{~d}^{\text {hi }} \mathrm{CD} 5^{+} \mathrm{B} 10$ cells with a regulatory function. ${ }^{17}$ To further validate the therapeutic application of B10 cells in vivo, we optimized the protocol for the efficient expansion of BAFF-induced B10 cells in culture. Splenic B cells were purified and cultured in the presence of BAFF for 72 hours, during which the percentage of $\mathrm{IL}-10$-producing $\mathrm{B}$ cells was increased significantly to $8.15 \% \pm 2.18 \%$, although approximately $20 \%$ of these BAFF-treated B cells were CD1 $d^{\text {hi }} \mathrm{CD}^{+}{ }^{+} \mathrm{B}$ cells as detected by flow cytometric analysis (Figure 2, A and B). Notably, IL-10-producing B cells substantially were expanded with a 10-fold increase in absolute numbers after 72 hours of culture. Moreover, approximately $30 \%$ of these $\mathrm{CD} 1 \mathrm{~d}^{\text {hi }} \mathrm{CD}^{+} \mathrm{B}$ cells were found to be $\mathrm{IL}-10^{+} \mathrm{B}$ cells, representing a major IL-10producing B-cell subset with a potent regulatory function in suppressing T-cell proliferation. In sharp contrast, $\mathrm{CD} \mathrm{d}^{\mathrm{lo}} \mathrm{CD}^{-} \mathrm{B}$ cells showed little IL-10 production with no immunosuppressive function (data not shown).

To evaluate the therapeutic potential of in vitro expanded B10 cells in suppressing autoimmune arthritis, we intravenously transferred various B-cell subsets into DBA mice on the day of second immunization. As shown in Figure $3 \mathrm{~A}$, CIA mice were treated with sorting-purified BAFF-induced CD1 $d^{\text {hi }} C D 5^{+}$ B10 cells, CD1 ${ }^{\text {lo }} \mathrm{CD}^{-}$B-ve cells, or CD1d ${ }^{\text {hi }} \mathrm{CD} 5^{+}$B10 cells

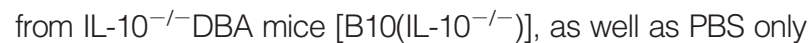
as sham control. Among four experimental groups with different treatments, B10 cell-treated mice showed an approximate 6 -day delay in arthritis onset, with only $75 \%$ of mice developing arthritis on day 20. However, the incidence of arthritis development in the other three control groups reached $100 \%$ on day 14 after the second immunization. As shown in Figure 3B, the clinical scores for arthritis severity were reduced markedly in B10 cell-treated CIA mice. On day 20 after the second immunization, joint samples of CIA mice from each group were prepared for H\&E staining and Safranin $O$ staining. Consistently, histopathologic analysis also showed remarkably reduced synovial hyperplasia, lymphocyte infiltration, cartilage damage, and bone erosion in the group of B10 cell-treated CIA mice when compared with other control groups (Figure 3, C and D). As shown in Figure 3D, the intact cartilage layers were observed only in joint tissue sections from CIA mice treated with B10 cells. To verify whether adoptive transfer of B10 cells can reduce bone destruction during CIA development, CIA mice from each group on day 40 after the second immunization were examined by microcomputed tomography analysis. As shown in Figure 3E, B10 cell-treated mice showed greatly reduced bone erosion with well-preserved joint structure as compared with control groups. Serum levels of total bovine collagen type II-specific IgG production were significantly lower in B10 cell-treated CIA mice than those in control groups. Further analysis on IgG isotypes revealed that serum levels of IgG1 and lgG2a were decreased substantially in the group of B10 cell-treated mice, whereas no significant difference in serum levels of bovine collagen type II-specific IgG2b and IgG3 was detected between the B10 cell-treated group and the other control groups (Figure 3F). Moreover, transferred B10 cells were found to be accumulated in inflamed joints (see Supplemental Figure S1 at http://ajp. amjpathol.org). Together, these results clearly showed the therapeutic effects of B10 cells on suppressing the development of autoimmune arthritis in mice. 


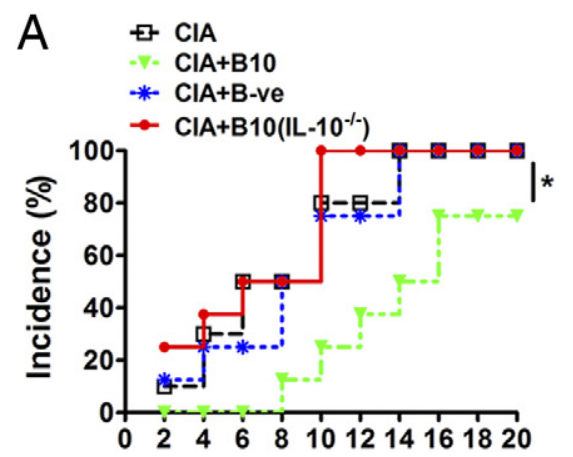

Days post $2^{\text {nd }}$ immunization

C

CIA

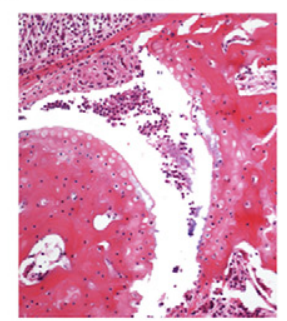

$\mathrm{D}$

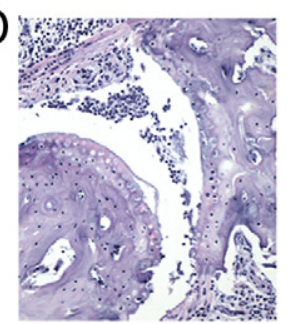

E

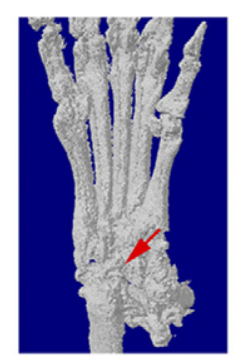

F

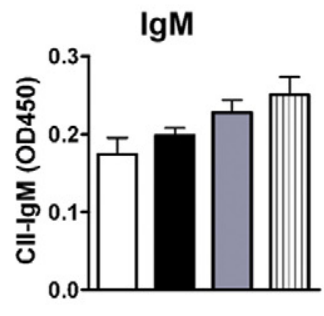

IgG2a
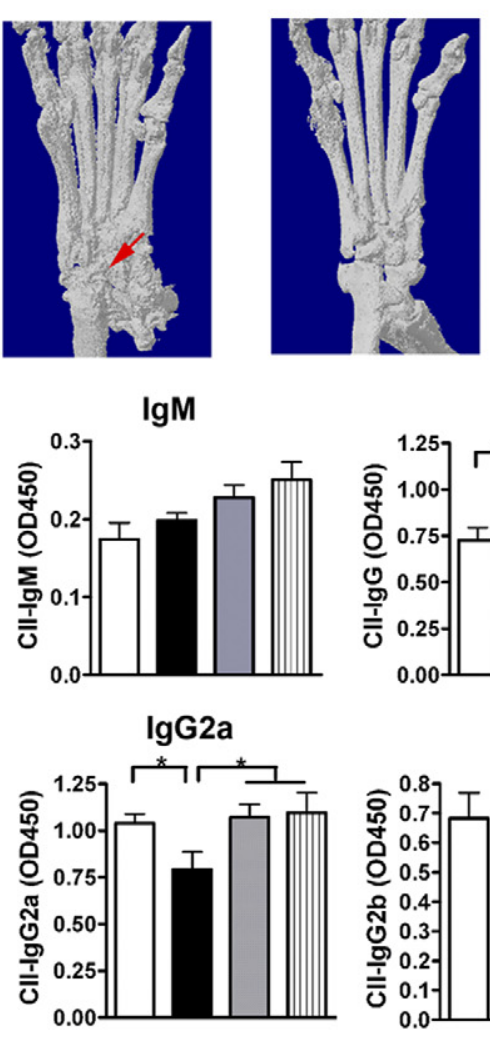

B

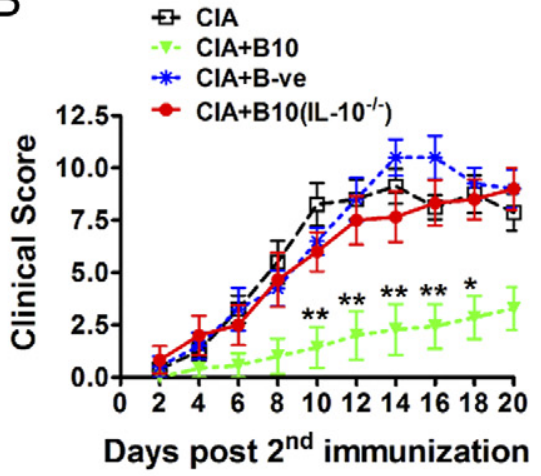

CIA+B-ve CIA+B10(IL-10-1-)
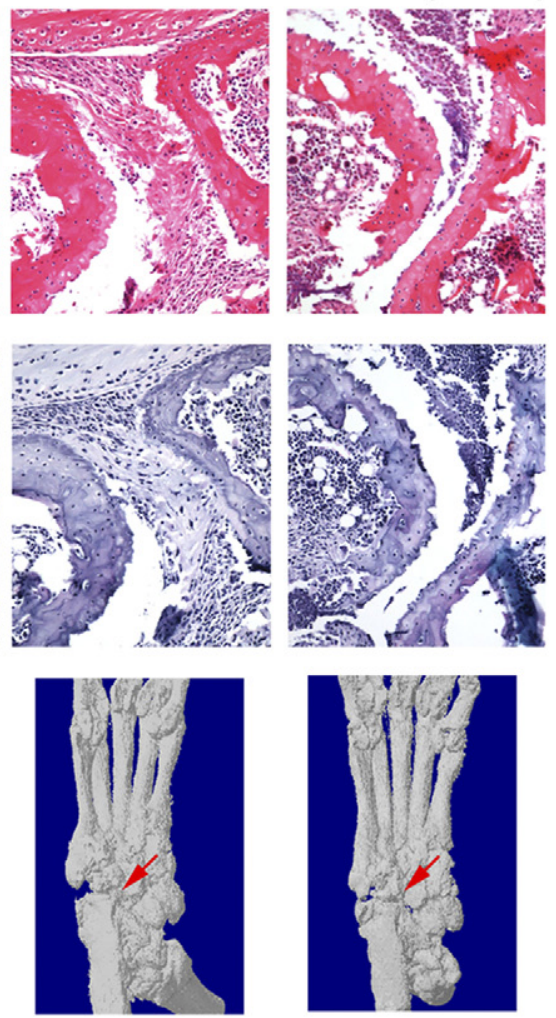

IgG
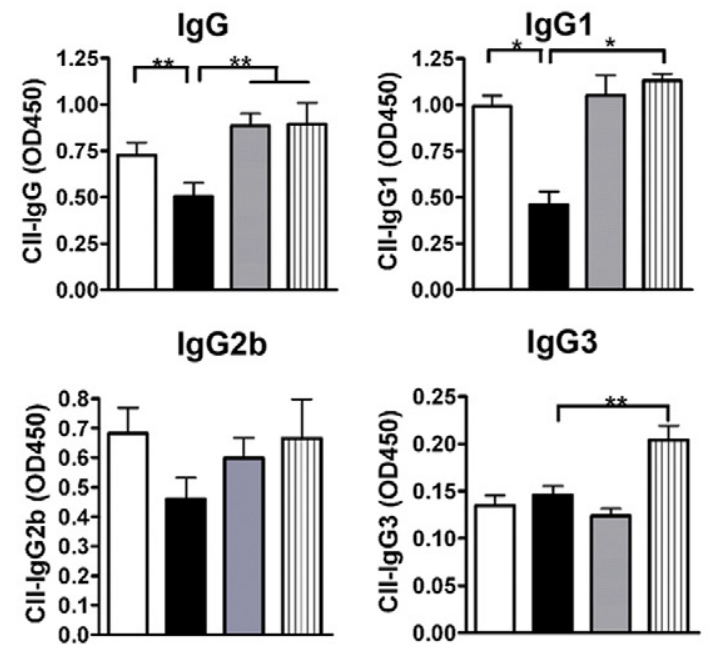

Figure 3. Adoptive transfer of B10 cells amelioates CIA development in mice. A: Sorting-purified B10 cells, B-ve cells, and B10 cells from IL-10 ${ }^{-/}$ DBA mice [B10 (IL-10 ${ }^{-1-}$ )] were injected intravenously into CIA mice on the day of the second immunization. Control CIA mice were injected with PBS only. The incidences of arthritis development in bovine collagen type II (CII)-immunized mice were measured. Statistical analysis of the data was performed by using the Fisher exact test $\left(n=8\right.$ for each group). ${ }^{*} P<0.05$. B: The clinical score for arthritis severity in various groups as described earlier was assessed daily for 20 consecutive days after the second immunization. Values (mean \pm standard error of the mean) are from the control group and treatment groups. The $P$ value was determined by the Mann-Whitney test ( $n=8$ for each group). ${ }^{*} P<0.05,{ }^{*}{ }^{*} P<$ 0.01. Cand D: Representative images of H\&E staining $(\mathbf{C})$ and Safranin $O$ staining $(\mathbf{D})$ are as shown (original magnification, $\times 200$ ). Cartilage is stained with an orange to red color. E: Represen tative microcomputed tomography scan photographs of hind paws of CIA mice on day 40 after the second immunization are shown. Red arrows indicate the sites of bone erosion. F: Serum levels of CII-specific total IgM, total IgG, IgG1, IgG2a, IgG2b, and IgG3 were measured by ELISA in CIA mice (white box), adoptive transfer of B10 (black box), B-ve (gray box), or B10 (IL-10 $0^{-/-}$) (hatched box). Values of mean \pm standard error of the mean are derived from 8 mice per group. ${ }^{*} P<$ $0.05,{ }^{\text {*** }} P<0.01$ 
A

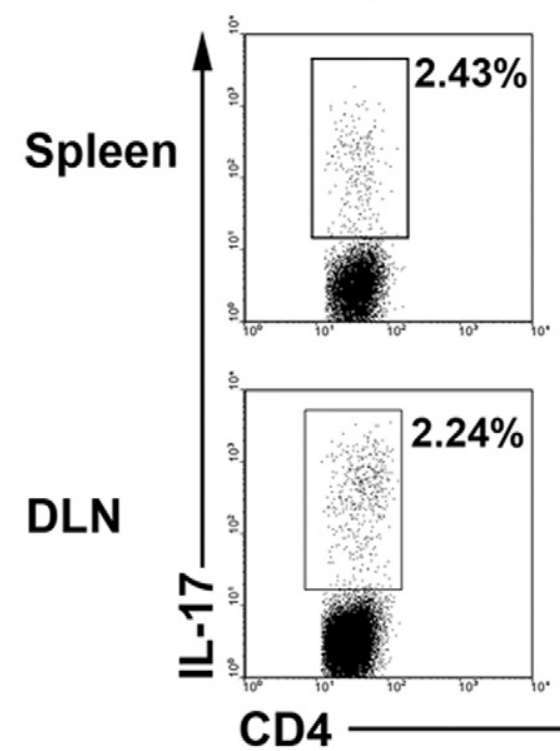

B
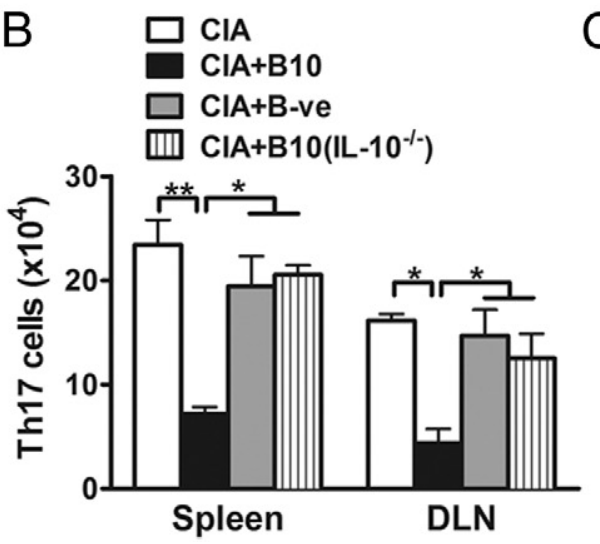

$\mathrm{CIA}+\mathrm{B} 10$
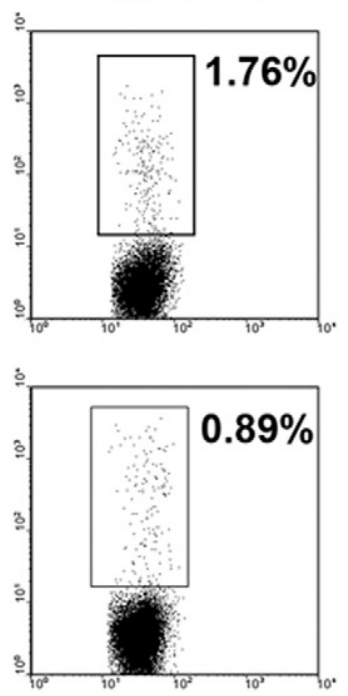

C

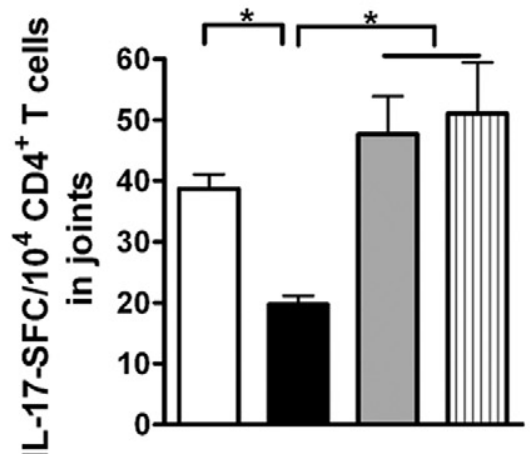

CIA+B-ve

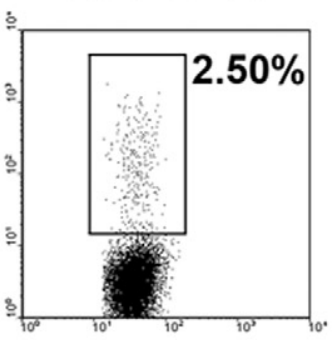

$\mathrm{CIA}+\mathrm{B} 10\left(\mathrm{IL}-10^{-1-}\right)$
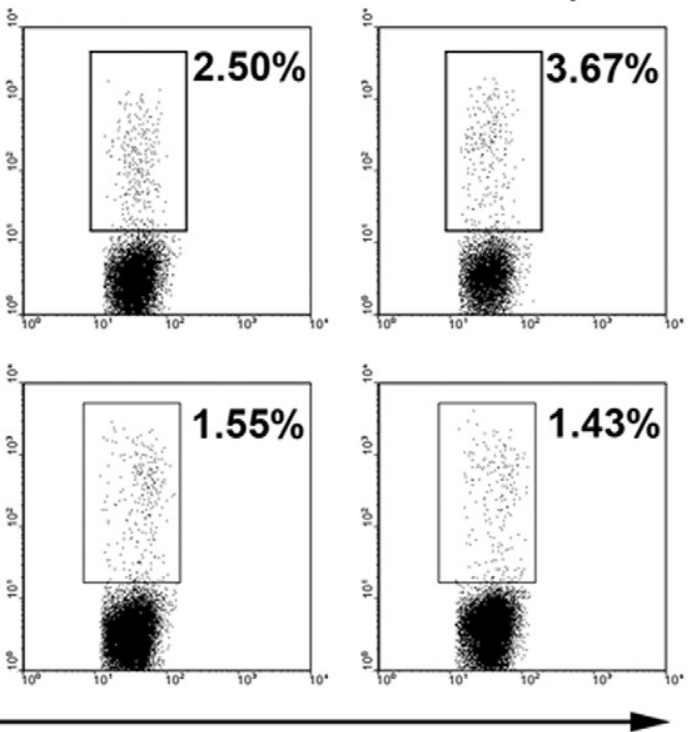

Figure 4. Adoptive transfer of B10 cells suppresses Th17 cell generation in CIA mice. A: Single-cell suspensions from spleen and draining lymph nodes (DLN) were collected on day 14 after the second immunization from CIA mice adoptive transfer of B10, B-ve, B10 (IL-10 ${ }^{-/}$) cells, and PBS only. Cells were stained with anti-CD 4 and followed by intracellular staining with anti-IL-17. The representative profiles show the frequencies of Th17 cells in the spleen and DLN of CIA mice with or without treatment. B: The total numbers of Th17 cells in spleen and DLN were enumerated. Values are the mean \pm standard error of the mean derived from 4 mice in each group. ${ }^{*} P<0.05,{ }^{* *} P<0.01$. C: Joint tissues from control CIA mice and CIA mice treated with different B-cell populations were digested for $\mathrm{CD}^{+}$ T-cell isolation. $\mathrm{CD}^{+} \mathrm{T}$ cells $\left(1 \times 10^{4}\right)$ were seeded in each well, and IL-17-spot-forming cells (SFC) were counted and compared from 4 independent experiments. ${ }^{*} P<0.05$.

\section{Adoptive Transfer of B10 Cells Suppresses Th17 Cell Generation in CIA Mice}

To further determine the immune mechanisms underlying the regulatory function of B10 cells in suppressing experimental arthritis, we sought to examine whether adoptive transfer of B10 cells affected Th17 cell generation in vivo. To monitor the frequency and cell numbers of Th17 cells in the spleen and draining lymph nodes, cell suspensions from these lymphoid organs of ClA mice transferred with different B-cell populations were prepared for the detection of Th17 cells by flow cytometric analysis. As shown in Figure 4, A and B, both frequencies and total cell numbers of Th17 cells were reduced significantly in B10 cell-treated CIA mice when compared with CIA mice treated with B-ve cells, B10 cells from IL-10 ${ }^{-1-}$ DBA mice or PBS only. To further evaluate the infiltration of Th17 cells in joint tissues, $\mathrm{CD}^{+}{ }^{+} \mathrm{T}$ cells from joint samples were isolated for the detection of IL-17-secreting $T$ cells by enzyme-linked immunosorbent spot assay. We also detected profoundly reduced Th17 cells in joints of B10 cell-treated CIA mice as compared with other control groups (Figure 4C). Thus, our findings suggest that adoptive transfer of B10 cells can affect the population size of Th17 cells in vivo.

\section{B10 Cells Suppress Th17 Cell Differentiation from Naive $C D 4^{+} T$ Cells in Culture}

To investigate whether B10 cells exert any direct effects on suppressing Th17 cell proliferation and/or differentiation in vitro, naive $\mathrm{CD} 4^{+} \mathrm{T}$ cells were cultured in the Th17 cell polarization medium. When co-cultured with B10 cells, an approximate $60 \%$ reduction of Th17 cells in both frequencies and total cell numbers was observed, as compared with naive T-cell induction alone or co-culturing with B-ve and B10 cells from IL-10 $10^{-1-}$ mice (Figure 5, $A$ and $B$ ). Moreover, enzyme-linked immunosorbent analysis confirmed the significantly reduced levels of IL-17 in the supernatant of T cells co-cultured with B10 cells (Figure 5C). Interestingly, when B10 cells were co-cultured with naive $\mathrm{CD} 4^{+} \mathrm{T}$ cells in Treg cell polarization medium, an approximate threefold increase of Treg cells in both frequencies and absolute numbers was observed when compared with naive T-cell induction alone or co-culturing with B-ve cells (see Supplemental Figure S2, A and B at $h$ ttp://ajp.amjpathol.org).

To further examine whether B10 cells can suppress Th17 cell proliferation, we used CFSE-labeled naive $\mathrm{CD} 4^{+} \mathrm{T}$ cells for 

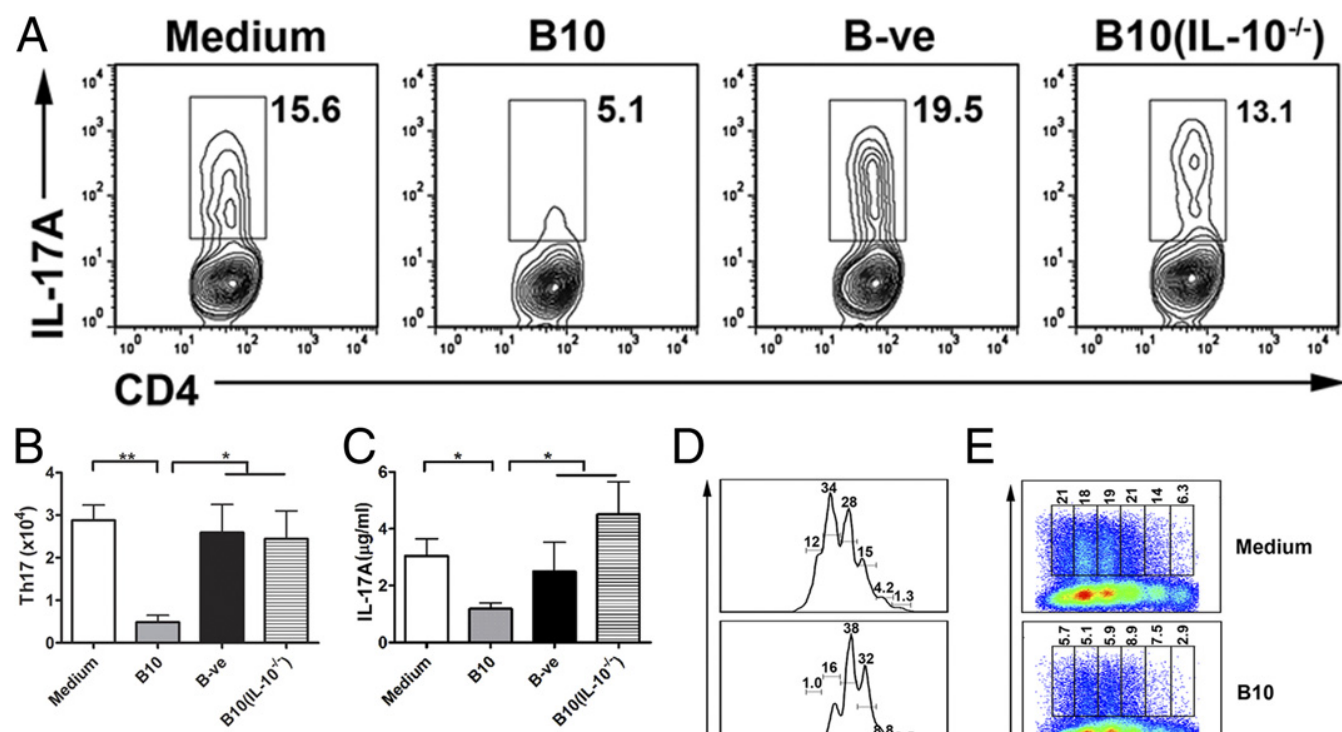

D

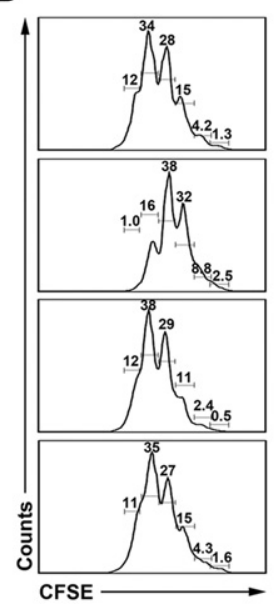

$\mathrm{E}$

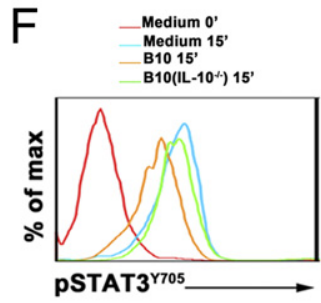

G

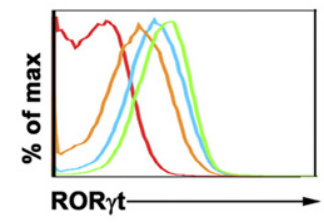

CFS

Figure 5. B10 cells suppress Th17 cell differentiation from naive $\mathrm{CD} 4^{+} \mathrm{T}$ cells in culture. A: Purified naive $\mathrm{CD} 4^{+} \mathrm{T}$ cells were cultured alone or with $\mathrm{B} 10$

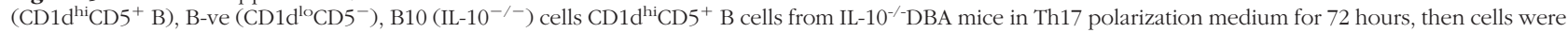
restimulated with PIM for 5 hours, stained intracellularly with anti-IL-17A, and analyzed by flow cytometry. Numbers in flow charts indicate the frequencies of Th17 cells. B: The total numbers of generated Th17 cells in each treatment were enumerated. Values (mean \pm standard error of the mean) are derived from five independent experiments. ${ }^{*} P<0.05,{ }^{* *} P<0.01$. C: ELISA determinants of IL-17A secretion in the supernatant from earlier-described co-culture conditions were shown as mean \pm standard error of the mean $(n=5)$. ${ }^{*} P<0.05$. D: CFSE-labeled purified naive splenic CD $4^{+}$T cells were cultured alone or with B10, B-ve B10 (IL-10 $10^{-1}$ ) cells in Th17 polarization medium for 72 hours, then cells were restimulated with PIM for 5 hours, stained with anti-IL-17A, and analyzed by flow cytometry. Gating on Th17 cells, each peak of Th17 cells indicates the division of Th17 cells in different culture conditions. Numbers in the graph represent the percentage of cells in each division. Results are representative of three independent experiments. E: CFSE-labeled CD $4^{+} \mathrm{T}$ cells were treated as described earlier. Each numeric figure in the graph represents the percentage of cells with the same number of divisions in the gated area. Results are representative of three independent experiments. F: Flow cytometric analysis of phosphorylated STAT3 (pSTAT3) (Y705) expression level is shown after naive T cells at 0 minutes (red line), naive $\mathrm{T}$ cells without treatment (blue line) or co-culturing with B10 cells (orange line), or co-culturing with B10 (IL-10 ${ }^{-/-}$) cells (green line) in the Th17 cell polarization medium for 15 minutes. G: Flow cytometric analysis of ROR $\gamma$ t expression level is shown after naive T cells were treated as described earlier.

co-culture. As revealed by flow cytometric analysis on Th17 cell divisions, co-culturing with B10 cells resulted in a marked reduction in Th17 cell proliferation (Figure 5D). Moreover, the frequency of Th17 cells generated in each division profoundly was decreased in B10 cell-treated culture, indicating that B10 cells suppress the generation of Th17 cells from naive T cells. Importantly, either B-ve cells or B10 cells from IL-10-deficient mice showed no or little effect on suppressing Th17 cell proliferation, which suggests that IL-10 is an important mediator for B10 cells exerting their suppressive function on Th17 cells (Figure 5E).

\section{B10 Cells Suppress STAT3 Phosphorylation and RORyt Expression in Naive CD $4^{+} \mathrm{T}$ Cells During Th17 Induction}

Because the differentiation of Th17 cells is initiated by activation of STAT3, which further induces the expression of ROR $y \mathrm{t},{ }^{23}$ we sought to determine whether B10 cells can reduce the STAT3 phosphorylation in naive T cells at the initial stage of Th17 cell differentiation. As shown in
Figure 5F, the amount of phosphorylated STAT3 (Y705) was decreased in B10 cell-treated naive T cells as compared with naive $\mathrm{T}$ cell alone or with the addition of B10 $\left(\mathrm{IL}-10^{-/-}\right)$cells in the Th17 cell polarization medium for a time interval of 15 minutes. Accordingly, the expression of ROR $y$ t in $T$ cells also decreased after treatment with B10 cells for 15 minutes (Figure 5G). Thus, these data suggest that B10 cells also can affect Th17 cell differentiation via inhibiting the STAT3-ROR $\gamma$ t pathway.

\section{B10 Cells Suppress Th17 Cell-Mediated CIA Development in IL-17-Deficient Mice}

Although it has been reported that IL-17 ${ }^{-1-}$ DBA mice are resistant to $\mathrm{ClA}$ induction, ${ }^{3}$ we sought to examine whether adoptive transfer of Th17 cells from wild-type DBA mice can trigger the development of arthritis in collagen-immunized $\mathrm{IL}-17^{-1-}$ mice. By using a cytokinecapture assay, we first purified in vitro differentiated viable Th17 cells (Figure 6, A and B). Then, we transferred purified Th17 cells alone or with B10 cells from DBA mice 

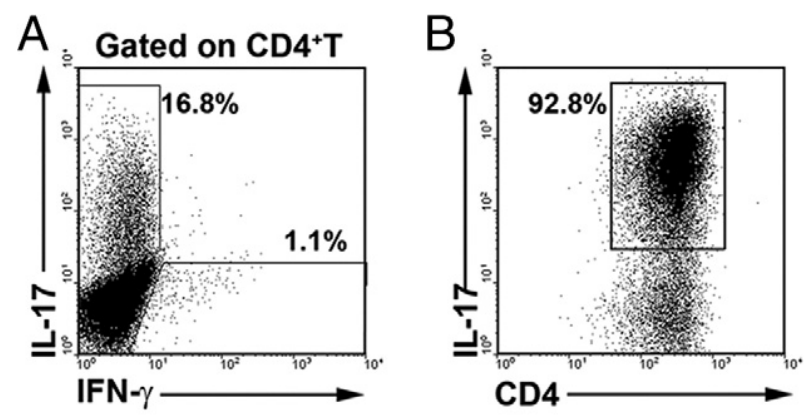

C

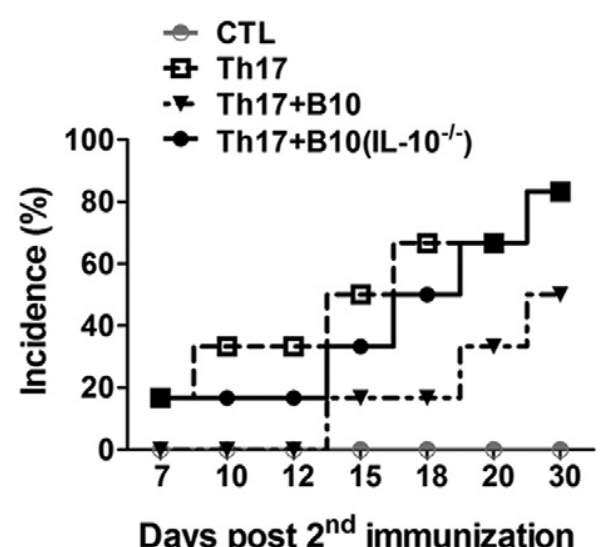

D

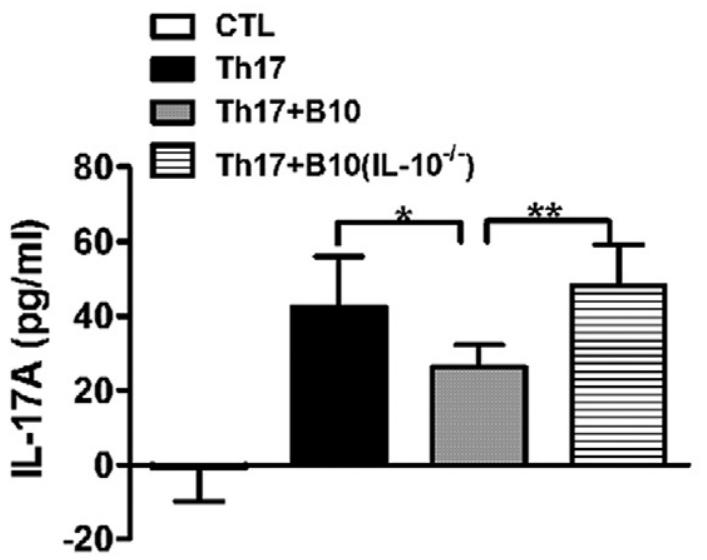

Figure 6. B10 cells suppress Th17 cell-mediated collagen-induced arthritis in $\mathrm{IL}-17^{-/-}$mice. A: Naive $\mathrm{CD} 4^{+} \mathrm{T}$ cells were cultured in the Th17 cell polarization medium for 4 days, and then cells were stained with anti-IL-17 and anti-interferon (IFN)- $\gamma$, followed by flow cytometric analysis. Gated on $\mathrm{CD}^{+}{ }^{+} \mathrm{T}$ cells, the percentage of induced IL- $17^{+} \mathrm{CD} 4^{+} \mathrm{T}$ cells and interferon- $\gamma^{+} \mathrm{CD} 4^{+} \mathrm{T}$ cells are as shown. $\mathbf{B}$ : In vitro induced Th17 cells were purified further by IL-17 cytokine capture assay and examined by flow cytometry. The purity routinely is higher than $90 \%$. C: $\mathrm{IL}-17^{-1-}$ DBA mice were used for CIA induction. Purified Th17 cells alone or with sorting-

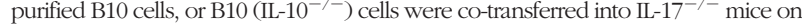
the day of the second immunization. Collagen II-immunized $\mathrm{IL}-17^{-/-}$mice were injected with PBS as sham control. The incidence of arthritis development in collagen II-immunized IL- $17^{-/-}$mice were as shown ( $n=6$ for each group). D: ELISA determinants of IL-17A secretion in synovial fluid from the earlier described mice were shown as mean \pm standard error of the mean $(n=6)$. ${ }^{*} P<0.05$, ${ }^{* * *} P<0.01$.

or IL-10 $-1-$ DBA mice into $\mathrm{IL}-17^{-1-}$ mice on the day of the second immunization. As shown in Figure 6C, adoptive transfer of Th17 cells triggered the onset of arthritis in $\mathrm{IL}-17^{-/-}$mice starting on day 7 after the second immunization, whereas no arthritic symptoms were observed in $\mathrm{IL}-17^{-/-}$mice without transfer of Th17 cells during a period of 30 days for observation. Compared with B10
(IL-10 ${ }^{-/-}$) cell-treated mice, co-transfer of B10 cells with Th17 cells delayed the development of arthritis by 7 days and only $50 \%$ of B10 cell-treated mice developed clinical symptoms of arthritis. Moreover, levels of IL-17A in synovial fluid also were decreased in B10 cell-treated mice (Figure 6D). Thus, these findings provide strong evidence that B10 cells ameliorate the development of arthritis via the inhibition of Th17 cells in vivo.

\section{Discussion}

In this study, we detected significantly reduced IL-10 ${ }^{+} \mathrm{B}$ cells at the acute phase of CIA induction. Adoptive transfer of in vitro expanded B10 cells has effectively suppressed the development of arthritis with a marked reduction of Th17 cells in mice. By using IL-17-deficient DBA mice, we clearly show that IL-17-producing CD4 ${ }^{+} \mathrm{T}$ cells are critically involved in the development of arthritis. Moreover, we have shown that co-transfer of B10 cells can remarkably delay the onset of Th17 cell-driven CIA development in IL-17-deficient mice. Together, these results have shown that IL-10-producing B10 cells ameliorate the development of arthritis by suppressing Th17 cell generation.

It has been well recognized that IL-23/Th17/IL-17 axis is critically involved in driving chronic inflammatory autoimmune diseases. ${ }^{24,25}$ The role of IL-17 in the pathogenesis of autoimmune arthritis in both human and mouse has been well demonstrated. ${ }^{1,26} \mathrm{IL}-17$ can increase the migration, chemokine expression, and invasiveness of synoviocytes, enhance metalloprotease secretion to cause cartilage damage, ${ }^{1}$ and act as an angiogenic mediator in RA. ${ }^{27}$ Previously, we have revealed a protective role of NK cells in the development of experimental arthritis, possibly via the suppression of Th17 cell generation. ${ }^{22}$ In the present study, we characterized the dynamic changes of Th17 cells during the progression of arthritis (Figure 1). Interestingly, the changes in both frequency and total cell numbers of Th17 cells in lymphoid organs and inflamed joints were correlated conversely with the kinetics of IL-10-producing B cells, especially at the acute phase of CIA development, which indicate a possible functional interaction between Th17 cells and B10 cells in vivo. Importantly, we also provide the evidence that adoptive transfer of purified in vitro induced Th17 cells can trigger the development of arthritis in IL-17-deficient DBA mice, which indicate an essential role of Th17 cells in CIA induction (Figure 6, C and D). To test whether B10 cells can directly affect Th17 cell generation, we have co-cultured naive CD4 ${ }^{+} \mathrm{T}$ cells with B10 cells in Th17 cell polarization medium. Notably, B10 cells directly can inhibit Th17 cell differentiation and proliferation in culture. Recent evidence indicates that the development and function of Th17 cells are critically dependent on STAT3. Selective depletion of STAT3 in T cells abrogates Th17 cell differentiation partially because the expression of $\mathrm{ROR} \gamma \mathrm{t}$ and $\mathrm{ROR} \alpha$ also is abrogated. ${ }^{28}$ Here, we show that B10 cells can reduce STAT3 phosphorylation and further decrease ROR $\gamma \mathrm{t}$ expression at the initial stage of inducing Th17 cells from naive T cells 
(Figure 5, F and G). Because it has become clear that activation of the STAT3-ROR $\gamma$ t pathway is indispensable for Th17 cell differentiation, our current findings thus highlight a novel function of B10 cells in regulating Th17 differentiation. Future studies are warranted to elucidate the underlying mechanisms by which B10 cells regulate the activation of the STAT3-ROR $\gamma$ t pathway.

T-cell plasticity has been well recognized. Many factors are known to influence the T-cell plasticity including cellular conditions, transcriptional circuitry, and chromatin modifications, and so forth. ${ }^{29}$ Thus, our current data cannot exclude the possibility that B10 also may induce Th17 cell transdifferentiation into other T-cell subsets or preferentially promote Treg cell differentiation by up-regulating Foxp3 expression. Of note, we also have found that B10 cells increase Treg cell differentiation in culture (see Supplemental Figure S2 at http://ajp.amjpathol.org). Nevertheless, it is plausible to reason that B10 cells may play an important role in T-cell plasticity.

Recent studies have shown that Th17 cells can induce B-cell proliferation and isotype class switching both in vitro and in vivo. ${ }^{30}$ Our findings that serum levels of IgG2a are decreased significantly in B10 cell-treated mice are consistent with the observed reduction in Th17 cells in these mice (Figures 3 and 4). However, it remains unclear whether B10 cells also directly can inhibit autoreactive B-cell proliferation and affect isotype class switch. Further studies may provide further insight in understanding the role of B10 cells in modulating autoimmune responses during arthritis development in both mouse and human.

The pathogenic roles of $\mathrm{B}$ cells in arthritis are characterized extensively, ${ }^{31}$ which have been illustrated further by the efficacy of B-cell depletion using rituximab (antiCD20) in treating RA patients. ${ }^{32}$ Although the underlying mechanisms still largely are unclear, van de Veerdonk et $\mathrm{al}^{2}$ showed that treatment with rituximab reduces the local Th17 response in RA patients, a potent effect associated with a better clinical outcome. However, this effect is abrogated in the absence of $B$ cells, which suggests that rituximab exerts its effect by directly depleting $B$ cells and reduces Th17 cells indirectly. Interestingly, this depletion therapy also has enhanced the generation of both Treg and Breg cell populations that may contribute to the long-term remission and maintenance of tolerance. ${ }^{33,34}$ Although B cell-targeted therapies in RA and other autoimmune diseases are very promising, ${ }^{35,36}$ long-term Bcell depletion possibly may lead to the development of immunopathology. Given that CD20 is expressed on B lymphocytes from the pre-B to mature $B$ cells, but not on plasma cells, ${ }^{21}$ current approaches for B-cell targeting cannot distinguish pathogenic B cells from Breg cells. Moreover, both numeric change and functional impairment of human Breg cells have been implicated in the disease pathogenesis of RA. ${ }^{6,8}$ Thus, further studies are needed to address whether the depletion of Breg cells may affect the long-term efficacy of B cell-targeted therapy. Nevertheless, our current study has shown that direct transfer of $\mathrm{B} 10$ cells into collagen-immunized mice effectively can delay the development of arthritis and markedly reduce joint damage by suppressing Th17 cell generation (Figures 3, 4, and 6). Moreover, transferred B10 cells can be detected in vivo for $>3$ weeks (unpublished data), which further suggest that B10 cell therapy possibly may exert a longer suppressive effect on arthritis development than the direct administration of IL-10, because IL-10 is known to have a short halflife in vivo. ${ }^{37}$

In summary, we have validated the efficacy of in vitro expanded B10 cells in ameliorating arthritis development in CIA mice. We further show that the therapeutic effects of BAFF-induced B10 cells on suppressing experimental arthritis possibly are mediated by inhibiting Th17 cell differentiation and proliferation in vivo. Therefore, further elucidation of functional interactions between $\mathrm{T}$ - and B-cell subsets may contribute to the development of new therapeutic strategies in treating human RA.

\section{Acknowledgments}

We thank Dr. William Lu and his colleagues (University of Hong Kong, China) for microcomputed tomography analysis, and technical support from the Faculty Core Facility and Wing Bun Chung (University of Hong Kong, China) for preparing tissue sections.

\section{References}

1. Hot A, Miossec P: Effects of interleukin (IL)-17A and IL-17F in human rheumatoid arthritis synoviocytes. Ann Rheum Dis 2011, 70:727-732

2. van de Veerdonk FL, Lauwerys B, Marijnissen RJ, Timmermans K, Di Padova F, Koenders MI, Gutierrez-Roelens I, Durez P, Netea MG, van der Meer JW, van den Berg WB, Joosten LA: The anti-CD20 antibody rituximab reduces the Th17 cell response. Arthritis Rheum 2011, 63:1507-1516

3. Nakae S, Nambu A, Sudo K, Iwakura Y: Suppression of immune induction of collagen-induced arthritis in IL-17-deficient mice. J Immunol 2003, 171:6173-6177

4. Lubberts E, Koenders MI, Oppers-Walgreen B, van den Bersselaar L, Coenen-de Roo CJ, Joosten LA, van den Berg WB: Treatment with a neutralizing anti-murine interleukin-17 antibody after the onset of collagen-induced arthritis reduces joint inflammation, cartilage destruction, and bone erosion. Arthritis Rheum 2004, 50:650-659

5. Pollinger B, Junt T, Metzler B, Walker UA, Tyndall A, Allard C, Bay S, Keller R, Raulf F, Di Padova F, O'Reilly T, Horwood NJ, Patel DD, Littlewood-Evans A: Th17 cells, not IL-17+(gamma)(delta) T cells, drive arthritic bone destruction in mice and humans. J Immunol 2011, 186:2602-2612

6. Mizoguchi A, Bhan AK: A case for regulatory B cells. J Immunol 2006, 176:705-710

7. Evans JG, Chavez-Rueda KA, Eddaoudi A, Meyer-Bahlburg A, Rawlings DJ, Ehrenstein MR, Mauri C: Novel suppressive function of transitional 2 B cells in experimental arthritis. J Immunol 2007, 178: 7868-7878

8. Yanaba K, Bouaziz JD, Haas KM, Poe JC, Fujimoto M, Tedder TF: A regulatory $B$ cell subset with a unique $C D 1 d$ hiCD5+ phenotype controls $T$ cell-dependent inflammatory responses. Immunity 2008, 28 : $639-650$

9. Matsushita T, Yanaba K, Bouaziz JD, Fujimoto M, Tedder TF: Regulatory $B$ cells inhibit EAE initiation in mice while other $B$ cells promote disease progression. J Clin Invest 2008, 118:3420-3430

10. Matsushita T, Horikawa M, Iwata Y, Tedder TF: Regulatory B cells (B10 cells) and regulatory $T$ cells have independent roles in controlling experimental autoimmune encephalomyelitis initiation and latephase immunopathogenesis. J Immunol 2010, 185:2240-2252

11. Matsushita T, Fujimoto M, Hasegawa M, Komura K, Takehara K, Tedder TF, Sato S: Inhibitory role of CD19 in the progression of 
experimental autoimmune encephalomyelitis by regulating cytokine response. Am J Pathol 2006, 168:812-821

12. Rafei M, Hsieh J, Zehntner S, Li M, Forner K, Birman E, Boivin MN Young YK, Perreault C, Galipeau J: A granulocyte-macrophage colony-stimulating factor and interleukin-15 fusokine induces a regulatory B cell population with immune suppressive properties. Nat Med 2009, 15:1038-1045

13. Blair PA, Chavez-Rueda KA, Evans JG, Shlomchik MJ, Eddaoudi A, Isenberg DA, Ehrenstein MR, Mauri C: Selective targeting of B cells with agonistic anti-CD40 is an efficacious strategy for the generation of induced regulatory T2-like B cells and for the suppression of lupus in MRL/Ipr mice. J Immunol 2009, 182:3492-3502

14. Haas KM, Watanabe R, Matsushita T, Nakashima H, Ishiura N, Okoch $\mathrm{H}$, Fujimoto M, Tedder TF: Protective and pathogenic roles for B cells during systemic autoimmunity in NZB/W F1 mice. J Immunol 2010, 184:4789-4800

15. Watanabe R, Ishiura $\mathrm{N}$, Nakashima $\mathrm{H}$, Kuwano $\mathrm{Y}$, Okochi $\mathrm{H}$, Tamak K, Sato S, Tedder TF, Fujimoto M: Regulatory B cells (B10 cells) have a suppressive role in murine lupus: $\mathrm{CD} 19$ and $\mathrm{B} 10$ cell deficiency exacerbates systemic autoimmunity. J Immunol 2010, 184:48014809

16. Mauri C, Gray D, Mushtaq N, Londei M: Prevention of arthritis by interleukin 10-producing B cells. J Exp Med 2003, 197:489-501

17. Yang $M$, Sun L, Wang S, Ko KH, Xu H, Zheng BJ, Cao X, Lu L: Novel function of $B$ cell-activating factor in the induction of IL-10-producing regulatory B cells. J Immunol 2010, 184:3321-3325

18. Gray M, Miles K, Salter D, Gray D, Savill J: Apoptotic cells protect mice from autoimmune inflammation by the induction of regulatory $B$ cells. Proc Natl Acad Sci U S A 2007, 104:14080-14085

19. Carter NA, Vasconcellos R, Rosser EC, Tulone C, Munoz-Suano A, Kamanaka M, Ehrenstein MR, Flavell RA, Mauri C: Mice lacking endogenous IL-10-producing regulatory B cells develop exacerbated disease and present with an increased frequency of Th1/Th17 but a decrease in regulatory T cells. J Immunol 2011, 186:5569-5579

20. Yanaba K, Hamaguchi $Y$, Venturi GM, Steeber DA, St Clair EW, Tedder TF: B cell depletion delays collagen-induced arthritis in mice: arthritis induction requires synergy between humoral and cell-mediated immunity. J Immunol 2007, 179:1369-1380

21. Zhang M, Ko KH, Lam QL, Lo CK, Srivastava G, Zheng B, Lau YL, Lu $\mathrm{L}$ : Expression and function of TNF family member $\mathrm{B}$ cell-activating factor in the development of autoimmune arthritis. Int Immunol 2005 17:1081-1092

22. Lo CK, Lam QL, Sun L, Wang S, Ko KH, Xu H, Wu CY, Zheng BJ, Lu $\mathrm{L}$ : Natural killer cell degeneration exacerbates experimental arthritis in mice via enhanced interleukin-17 production. Arthritis Rheum 2008 , 58:2700-2711

23. Dong C: TH17 cells in development: an updated view of their molecular identity and genetic programming. Nat Rev Immunol 2008, 8:337-348

24. Toussirot $\mathrm{E}$ : The IL23/Th17 pathway as a therapeutic target in chronic inflammatory diseases. Inflamm Allergy Drug Targets 2012, 11(2): $159-168$

25. Duvallet E, Semerano L, Assier E, Falgarone G, Boissier MC: Interleukin-23: a key cytokine in inflammatory diseases. Ann Med 2011, 43:503-511

26. Lubberts $\mathrm{E}$, Koenders $\mathrm{MI}$, van den Berg WB: The role of T-cell interleukin-17 in conducting destructive arthritis: lessons from animal models. Arthritis Res Ther 2005, 7:29-37

27. Pickens SR, Volin MV, Mandelin AM 2nd, Kolls JK, Pope RM, Shahrara S: IL-17 contributes to angiogenesis in rheumatoid arthritis. J Immunol 2010, 184:3233-3241

28. O'Shea JJ, Murray PJ: Cytokine signaling modules in inflammatory responses. Immunity 2008, 28:477-487

29. Murphy KM, Stockinger B: Effector T cell plasticity: flexibility in the face of changing circumstances. Nat Immunol 2010, 11:674-680

30. Mitsdoerffer M, Lee Y, Jager A, Kim HJ, Korn T, Kolls JK, Cantor H, Bettelli E, Kuchroo VK: Proinflammatory T helper type 17 cells are effective B-cell helpers. Proc Natl Acad Sci U S A 2010, 107:1429214297

31. Mauri C: Regulation of immunity and autoimmunity by B cells. Curr Opin Immunol 2010, 22:761-767

32. Chabaud M, Durand JM, Buchs N, Fossiez F, Page G, Frappart L, Miossec P: Human interleukin-17: a T cell-derived proinflammatory cytokine produced by the rheumatoid synovium. Arthritis Rheum 1999, 42:963-970

33. Ruan Q, Kameswaran V, Zhang Y, Zheng S, Sun J, Wang J, Devirgiliis J, Liou HC, Beg AA, Chen YH: The Th17 immune response is controlled by the Rel-ROR\{gamma\}-ROR\{gamma\}T transcriptional axis. $J$ Exp Med 2011, 208:2321-2333

34. Roark CL, French JD, Taylor MA, Bendele AM, Born WK, O'Brien RL: Exacerbation of collagen-induced arthritis by oligoclonal. IL-17-producing gamma delta T cells. J Immunol 2007, 179:5576-5583

35. Eisenberg R, Albert D: B-cell targeted therapies in rheumatoid arthritis and systemic lupus erythematosus. Nat Clin Pract Rheumatol 2006, 2:20-27

36. Dorner T, Radbruch A, Burmester GR: B-cell-directed therapies for autoimmune disease. Nat Rev Rheumatol 2009, 5:433-441

37. Sloane EM, Soderquist RG, Maier SF, Mahoney MJ, Watkins LR, Milligan ED: Long-term control of neuropathic pain in a non-viral gene therapy paradigm. Gene Ther 2009, 16:470-475 